administering the muzzling order-rabies has not been stamped out in Wales, does not touch the real merits of the question.

$\mathrm{Mr}$. Long, the former President of the Buard of Agriculture, who has proved himself thoroughly well instructed in the whole question of rabies, has with laudable firmness resisted the outcry and the repeated assaults of the uninstructed sentimentalists, and as a result was able to demonstrate that by the strict carrying out of the muzzling order rabies in England was checked and was almost reduced to extinction, though at first it was so prevalent as to be really alarming. It seems hopeless to discuss this or any other dog-question with people who, in the face of all expert opinion as regards prevention of rabies, and particularly against the opinion of sensible owners of dogs, can write that "the muzzling order and the muzzle are a gross and wanton cruelty to animals."

But even if it were not an exaggeration, as we are persuaded it is, that the owners of dogs in general object to the muzzling order and consider it a cruelty to animals, what about the human species? Human beings who are not niembers of the executive committee of the National Canine Defence League regard the muzzling order as an important safeguard. One of the duties of the State is to protect the health and lives of its citizens. Hydrophobia of man is one of the most terrible diseases, and the slaughter of stray dogs and the muzzling of all dogs in places where rabies is rife has been proved to be at present the best and only means to prevent the spread of the disease to man. Besides, it should be the interest of owners of valuable animals to insist on the retention and strict carrying out of a measure which to a very large extent insures against the spread of rabies and consequent loss-seemingly of indifference to the members of the Canine Defence League.

\section{RECENT WORK OF THE GEOLOGICAL SURVEY.}

THE Report referred to below ${ }^{1}$ shows that the Geological Survey continues with activity and success its investigation of the geology of these islands. It bears witness to a large amount of steady and useful routine work, which may not make much show, but which will contribute to our knowledge of the detailed structure of these islands and in some instances will have direct economic usefulness. Among the more interesting scientific results of the year's work, the progress of the re-examination of Cornwall has brought to light evidence of a younger granite than the main mass of that rock, showing that the granitic intrusions form a somewhat more complex series than had been supposed. The clue, however, to the detailed structure of the so-called "killas" and the boundaries between the true Devonian and older rocks still eludes the keen eyes with which the surveyors are searching for it. If we could hope that the appointment of a mining geologist would do anything towards reviving the decayed mining industry of the region, we should still more rejoice in this increase to the strength of the staff. Another of the problems which for years past has baffied the officers of the Survey is that of the Old Red Sandstone of South Wales. They are still unable to draw any satisfactory line between the lower and upper divisions of the system. If the key is not found before the western coast is reached, we can hardly hope that it will be discovered in any part of this region.

Some interesting discoveries were made during the year in Scotland. Foremost among these is the finding of proof that the granite of south-west Argyllshire has

1 " Summary of Progress of the Geological Survey of the United Kingdom and Museum of Practical Geology for rgor."

$$
\text { NO. } 1730 \text {, VOL. 67] }
$$

invaded and altered a portion of the Lower Old Red Sandstone series of Lorne. The importance of this new fact lies in its relation to the history of the metamorphism and igneous protrusions of the Scottish Highlands, for it shows that some of the granitic masses, like those of Galloway and Leinster, are certainly post-Silurian in age. Another notable "find" is that of the zone of Pecten asper in the island of Scalpay and of Upper Cretaceous rocks in the sound of Soay.

In Ireland, the energies of the Survey are now concentrated on the Drift, with the view of preparing accurate maps of the superficial deposits of the country. But under Mr. Lamplugh's direction, the geological interest of the glacial geology is not likely to be lost sight of. One of the features of the work in the Dublin district was the finding of evidence which seems to support the view that the eskers represent water-channels which existed under the ice-sheet.

A new arrangement has been made in this Summary. Its materials are grouped by districts instead of, as formerly, by formations. The change will no doubt save trouble in the preparation of the volume, but it gives a great deal more to the geologist who wishes to ascertain what additions to our knowledge the Survey has been able to make in any particular part of the geological record. Another change is the omission of the Director's name from the book. It surely cannot have been the wish of those who wield the new brooms at South Kensington to sweep Mr. Teall's name clean out of his Report.

\section{PROF. P. P. DEHERAIN}

DEHERAIN (b. I 830 , d. 1902), who in 1887 succeeded to Boussingault's place in the Académie des Sciences, was, for the last twenty-two years of his life, professor of vegetable physiology as applied to agriculture at the Muséum in Paris. His early work was chiefly agricultural, and included researches on calcium phosphate, on the salts of potassium, \&c. ; he was author of a "Cours de Chimie agricole," and it should not be forgotten that he founded the Annales agronomiques. In the region of pure physiology, he was author of a number of memoirs, of which those written in collaboration with Maquenne, Moissan and others are perhaps especially well known. He worked at gaseous interchange, including the absorption of oxygen by succulents and by oily seeds, also at the assimilation of $\mathrm{CO}_{2}$, being especially interested in the action of the different parts of the spectrum on this process. His researches extended to other subjects, such as transpiration, the assimilation of free nitrogen and denitrification.

A sympathetic appreciation of his personal character and of his career as a teacher is given by his former pupil, Maquenne, in La Nature of December I 3 , to which we acknowledge our indebtedness. Although Déherain's name is not associated with any great discovery, he deserves the place he won for himself in the annals of plant-physiology and the honour due to one who dies in harness.

F. D.

\section{TRANSATLANTIC WIRELESS TELEGRAPHY.}

MR. MARCONI'S latest success is a wonderful I achievement. Messages have been exchanged in stations at Glace Bay, Cape Breton, and Poldhu, Cornwall. Transatlantic wireless telegraphy has thus been successfully established; and the persistent effort which has enabled this result to be accomplished merits the fullest recognition. The messages which we print from the Times represent the inauguration of a system of 